\title{
Scientific Ideas Included in the Concepts of Bioacoustics, Acoustic Ecology, Ecoacoustics, Soundscape Ecology, and Vibroacoustics
}

\author{
Agnieszka OZGA \\ AGH University of Science and Technology \\ Faculty of Mechanical Engineering and Robotics \\ Department of Mechanics and Vibroacoustics \\ Al. Mickiewicza 30, 30-059 Kraków, Poland; e-mail: aozga@agh.edu.pl
}

(received February 26, 2017; accepted April 7, 2017)

\begin{abstract}
The paper discusses the research areas which are placed in the modern science on the borderline between ecology and acoustics. It is explained what ideas are included in the concepts of bioacoustics, acoustic ecology, ecoacoustics, and soundscape ecology. The results obtained in these domains are compared with those received in vibroacoustic research presented at the Polish WIBROTECH conference cycle. The paper suggests an inventory of research topics connected with acoustics and ecology. In the second part of the paper the author presents the possibilities of ambisonic technology of recording and listening to sounds for the analysis in bioacoustic research.
\end{abstract}

Keywords: bioacoustics; soundscape ecology; acoustic ecology; ecoacoustics; vibroacoustics.

\section{Introduction}

In contemporary science we encounter four overlapping concepts: bioacoustics, acoustic ecology, ecoacoustics, and soundscape ecology. These concepts denote the areas of science that merge with one another and it would be hard to indicate where acoustic ecology ends and ecoacoustic starts. As for these two concepts, the division seems continental or phraseological rather than scientific. Moreover, comparing the results of research conducted in these two domains, we can always find a part that is shared with research conducted parallelly in medicine or vibroacoustics.

The first part of the article provides answers to the following three questions:

1. Which concepts describe what is happening in modern science on the borderline of ecology and acoustics?

2. In what way does vibroacoustics participate in these scientific ideas?

3. In what way could we arrange a list of research topics connected with acoustics and ecology?

The second part of the paper discusses application of ambisonic technology of recording and decoding sounds in bioacoustic research.

\subsection{Bioacoustics, acoustic ecology, ecoacoustics, and soundscape ecology}

Bioacoustics is the oldest among the above mentioned research areas and the youngest branch of zoological sciences (TEMBROCK, 1959). It was developed in Pennsylvania, where in 1956 the views and experiences revalent in this domain were discussed and the International Committee of Biological Acoustics was established. Bioacoustics studies and systematises sounds produced by animals. This type of vocalisation is mostly produced by the animals' sound organs. Today, according to the International Bioacoustics Council (IBAC, website http://www.ibac.info/), which was founded in Århus, Denmark, in September 1969, bioacoustics is concerned, on the one hand, with sound production in animals, including sound reception capabilities and mechanisms of animal hearing, and on the other hand with sound propagation in water and air. This area of science includes research of vibrational communication of insects, biosonar or echolocation of bats and dolphins, ultrasonic signals of insects, rodents, bats, and dolphins, infrasonic signals of large mammals. There is also research dealing with ethology of animal acoustic communication, evolution, 
ontogeny, and development of acoustic behaviour, relationships between animal sounds and their environment, effects of man-made sounds on animals. Moreover, bioacoustics can also be applied in wildlife monitoring and in pest control (FABIRKIEWICZ, 1999).

Soundscape was introduced by Alvin Lucier. Yet, it was the composer R. Murray Schafer (KAPELAŃSKI, 2005; Schafer, 1977; 1978; Wrightson, 2000) who defined the concept of generally understood sound environment at a given time and place. In turn, soundscape ecology is a science that analyses the relations between man and his surroundings, using the sound. Bearing in mind that the concept of ecology is defined both as a domain of biology studying organisms in their natural environment and as actions supporting protection of the environment, it is hard to accept restrictions in combining two domains - ecology and acoustics in a single relation of the human with his environment. Hence, two other notions that have appeared in science are acoustic ecology and ecoacoustics.

The scientists dealing with acoustic ecology, ecoacoustics and soundscape ecology are gathered in two different scientific organizations: the International Society of Ecoacoustics (ISE, website https://sites.google.com/site/ecoacousticssociety/about) and the World Forum for Acoustic Ecology (WFAE, website http://wfae.net/index.html). WFAE was established during the first international Conference on Acoustic Ecology in Banff, Canada, in August 1993. The first ISE meeting entitled "Ecology and acoustics: emergent properties from community to landscape" took place in Paris, France, between 16 and 18 June 2014. The conference was set up by two experts of the ecological investigation Jérôme Sueur (Sueur, 2008; Sueur, FARINA, 2015) and Almo Farina (FARINA, 1998; 2014; PiJANowski et al., 2011).

The international association WFAE deals with social, cultural, and ecological aspects of the sonic environment and unites members who share a common concern for the state of the world's soundscapes. In this sense, acoustic ecology seems to be a broader concept than soundscape ecology. In turn, ecoacoustics is defined by the ISE as a science that investigates natural and anthropogenic sounds and their relationship with the environment including populations and communities. This is connected with the increased interest in sounds in the context of information concerning the condition of ecological systems.

The first attempt at systematic division of research topics into those pertaining acoustic ecology, ecoacoustic and soundscape ecology will probably be made in 2017 at the Conference on Sound + Environment organized by the University of Hull in the UK. The scientists dealing with the research topics in these areas are obliged to choose one of three panel ses- sions as the place and time appropriate to present their most recent results. Apart from sound art, the scientific committee bringing together artists and scientists has introduced the following panels: acoustic space and psychoacoustics, psychogeography, acoustic communities, social, cultural and environmental sustainability, environmental aesthetics, environmental politics, structural monitoring, urban design and planning, environmental health. However, the topics discussed at the Conference will not include a panel devoted to vibroacoustics, which is basically the domain of science studying all vibration and acoustic processes taking place in the nature, technology, machinery, appliances, means of transport, and communication, that is, in the broadly understood environment

\subsection{Common features of vibroacoustic and acoustic ecology}

Vibroacoustics, was developed on the basis of investigations connected with protection of the environment from vibrations (ENGEL, 1993) and comprises scientific problems closely connected with the topics (ENGEL, 2004; 2007) investigated by acoustics connected both with soundscape and ecology. For instance, scientific research conducted by the Acoustic Ecology Institute of Santa Fe, New Mexico, USA were focused on the wind farm noise resources (PEARCE-HigGins, 2009), which are now studied also by a group of scientists dealing with vibroacoustics at the AGH University of Science and Technology in Cracow (KASPRZAK et al., 2014; WszoŁeK et al., 2014). Research into green transport may serve as another example of the area where studies aimed at reduction of vibration amplitudes in vehicles (SIBIELAK et al., 2013; KONIECZNY et al., 2013) refer to working conditions of people, while investigations aimed at reduction of noise (Kompata, 2005; StęPIEŃ, 2016) and emissions of exhaust gases also include all kinds of natural habitats and species recognised as valuable or endangered in Europe in (GuŽAs et al., 2006; PIECHOWICZ et al., 2015; WICIAK et al., 2015). Polish scientists executing vibroacoustic studies concerning the processes propagation of the energy of mechanical vibrations and noise due to a variety of influences necessary for proper functioning of machinery (BATKO et al., 2008; DĄBROWSKI, 1992; DĄBROWSKI et al., 2013; JABlonski, Ozga, 2013; Klekot, 2013; OzgA, 2013; 2014, RUSINEK et al., 2013a; 2013b) present their newest results at the Polish annual conference called WIBROTECH. It should be mentioned that the latest two conferences were devoted to the achievements of Polish eminent specialists in vibroacoustics, the professors:

- Wojciech Batko, whose works are mostly focused on the problems of dynamics, vibroacoustics, and technological diagnostics of machinery (2016). 
- Zbigniew Dąbrowski, who deals with modelling of reciprocal relations between propagation of various forms of vibroacoustic energy in the two basic challenges faced by this domain of science maximum reduction of vibroacoustic threats and technological diagnostics (2017).

Another area of science is the subject common to vibroacoustics and acoustic ecology, namely, environmental health. The methods applied in vibroacoustics like computer simulation that can be used to test or optimise the vibroacoustic characteristics of middle ear implants (KELLY, 2003), or examination of prototypes of machines and appliances (BARANSKI, KOZUPA, 2014) are closely connected with improvement of quality of life and health of patients (KAsprzaK, 2014) or workers. Simply, studies in contemporary science are interdisciplinary (RYŻAK et al., 2016, DĄBRowski DzIURDź, 2015); it is continually more difficult to recognise them as belonging to one domain of science or carry them out effectively without any cooperation. The second chapter of this paper discusses an example of such research.

\subsection{Proposed ordering of concepts connected with acoustics and ecology}

In the attempt of introducing certain order into the dynamically transforming science as well as the terminological division between particular concepts of bioacoustics, acoustic ecology, ecoacoustics and soundscape ecology and vibroacoustic acoustics seems to be the natural indicator of the divisions (Fig. 1) Then we should introduce another division, into the research dedicated to humans and to nature. It is possible to add another panel, combining these two targets. In a further step we should divide the studies dedicated to humans into the following sections: medicine areas, vibroacoustics when we consider simultaneously propagations of vibrations and sound and soundscape ecology when a single relation between the human and his acoustic environment is studied. The nature section should include bioacoustics as the domain of science that systematises the sounds produced by animals. Acoustic ecology should be present in both sections, but whenever this expression is used, a full description informing whether the investigations consider humans or animals should be provided. In my opinion the concept of ecoacoustics brings about unnecessary terminological confusion, so I do not place them in Fig. 1. Examination of the acoustic environment in all possible aspects has been ascribed to the section dealing with humans; nevertheless, similar to the structural monitoring, it may belong to all three sections. A detailed division of medicine or veterinary medicine into categories (if the need arose) should be left to the experts in the domains. The remaining topics should be dealt with in a similar way.

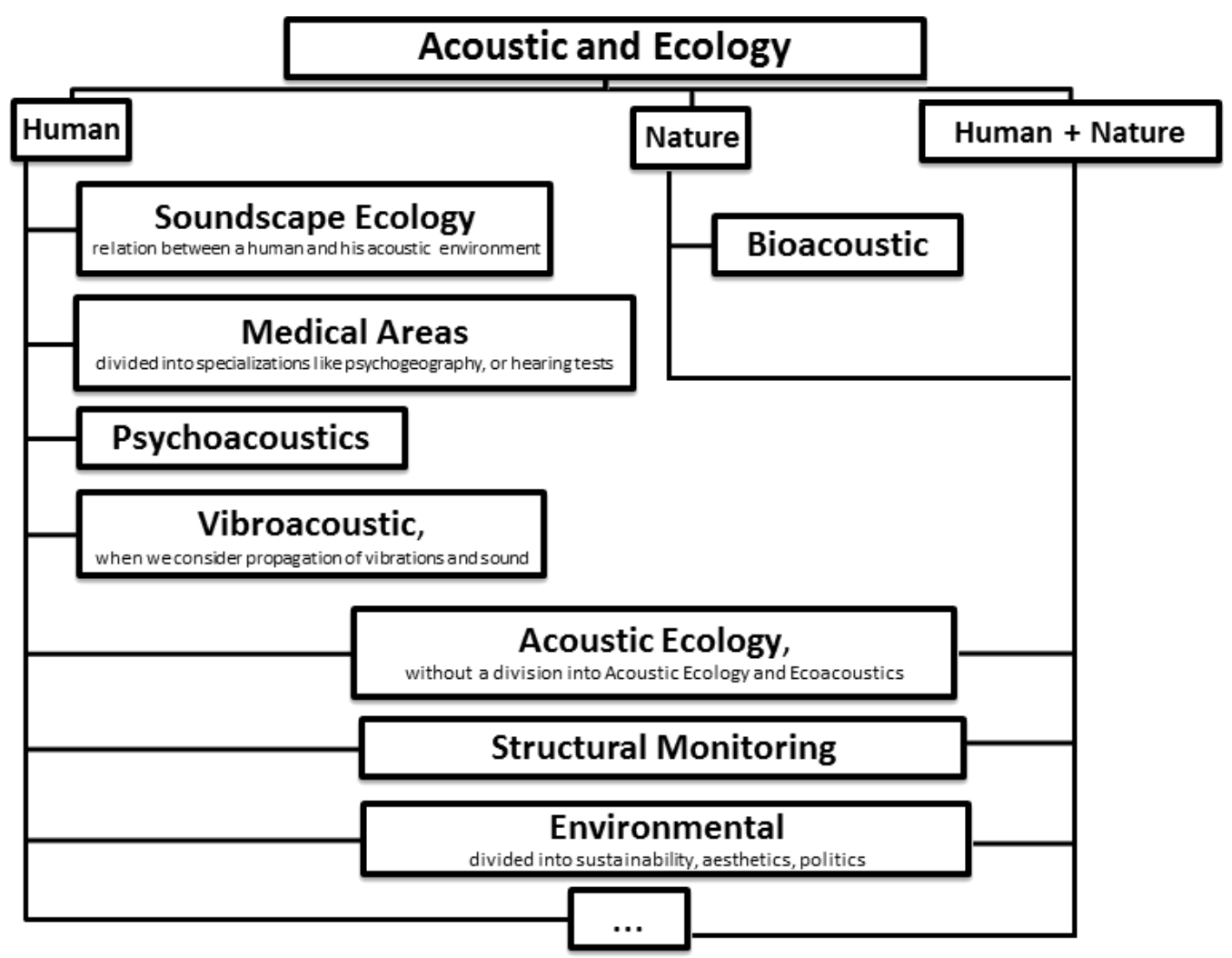

Fig. 1. Ordering of concepts connected with ecology and acoustics. 


\section{Pilot bioacoustic investigations executed in Niepołomicka forest, Nature 2000}

It has already been mentioned that due to its interdisciplinary character it is getting continually more difficult to conduct research individually or in a homogenous - as regards their specialisation - group of scientists. For instance, the initial idea of pilot investigations conducted by the researchers from the Department of Mechanics and Vibroacoustics of the AGH University of Technology in Niepołomicka forest in 2014 was structural monitoring - recording of transformations that take place in this area causing fragmentation and exerting significant influence on natural resources. In the area of the forest and its surroundings new investments are made continually - the railway is being modernised to serve Pendolino trains, A4 motorway is being developed. Niepołomicka forest is an area exploited by agriculture, forestry, and hunting. It is also a recreational spot intensely used by local inhabitants and tourists.

The structural monitoring project allowed us to obtain several recordings that enrich the bioacoustic audio library. These random recordings of very good quality cannot be classified by the data concerning the species of a given animal, its age, sex, or development stage by a specialist in acoustics. On the other hand, biologists who specialise in monitoring of the Nature 2000 areas are not able to execute recordings using the newest innovations like recording and decoding of sounds in ambisonic technology. Moreover, both these groups of scientists should try to get acquainted with the most recent achievements in monitoring with video technology.

\subsection{Characteristics of Niepołomicka forest, Nature 2000 PLB120002}

Niepołomicka forest is one of the most important egg clutching refugia of Ural owl Strix uralensis, middle spotted woodpecker Dendrocopos medius, collared flycatcher Ficedula albicollis, and black woodpecker Dryocopus martius. Thus, it has become a special protection area for birds "Puszcza Niepołomicka" No PLB120002. Moreover, a centre for maintenance breeding of European bison (Bison bonasus) threatened with extinction has been established there. The forest is inhabited by the following mammals: roe deer, red deer, European badgers, wild boars, foxes, hares, beavers (Castor fiber), stoats (Mustela erminea), greater mouse-eared bats (Myotis myotis), whiskered bats (Myotis mystacinus), fat dormouse (Glis glis), common shrew (Sorex araneus), and Eurasian pygmy shrew (Sorex minutus). Niepołomicka forest is also a habitat for lizards, grass snakes, common vipers, common and green toads, European tree frogs and smooth newts. More than 30 species of protected plants, including royal fern (Osmunda regalis) grow here.

The paper presents a small fragment of the recorded material for study - an analysis has been conducted of a cry of a frightened male roe deer recorded with surround sound microphones which can capture not only the atmosphere of Niepołomicka forest but also the dynamics of all events.

\subsection{Bioacoustic studies}

International Bioacoustics Council requires that the report of the recording should include the following information:

\section{Data concerning the microphone}

The recording was executed using a microphone set SoundField ST350 in the 4-channel protocol; saved as wav file with the parameters for bit sample 24, and sample rate 48000 , called B-format *.wav. Ambisonic technology allows for a broad range of interpretations of a recorded event in the lab conditions. Sound phenomena occurring in the natural environment may be decoded in the spatial (3-D) format. The microphone also records the frequencies of vibrations occurring in the organisms producing sounds above $20 \mathrm{kHz}$ (Fig. 2, line $\mathrm{A}$ and box $\mathrm{C}$ and $\mathrm{D}$ ), which corresponds with the human hearing limits (Kleczkowski, Pluta, 2012).

2. Data concerning the distance between the microphone and the source of the sound

Due to the fact that the roe deer was accidentally frightened away from where it had spent the night, the distance between the microphone and the source of the sound is between a few meters (boxes B, C, and beginning D, Fig. 2) to about a dozen of meters (box E, Fig. 2), which has been shown in the spectrogram.

Listening to the file recorded using ambisonic technique gives us an impression that monosyllable, single sounds, which constitute a full phonological unit, and are marked in the spectrogram with rectangles $\mathrm{B}, \mathrm{C}$, and $\mathrm{D}$, were produced at the same spot. The differences concerning their duration or the range of the top frequencies are connected with the changes in intensity (power of the voice) of the second and third bark. In the rectangles $\mathrm{D}$ and $\mathrm{E}$ we have to do with a series composed of regularly repeating single voices. At the first stage of area D the series have no stabilised rhythm (Fig. 3). Data from literature indicate that a male roe deer following females produces quiet series of bellowing cries composed of five to seven cries. The recording of barks produced by a startled male reveals a different series of cries changing with the increased distance from the danger. These data are an added value to the bioacoustics investigations. Soundscape recordings allow for an analysis of the changing location of the 


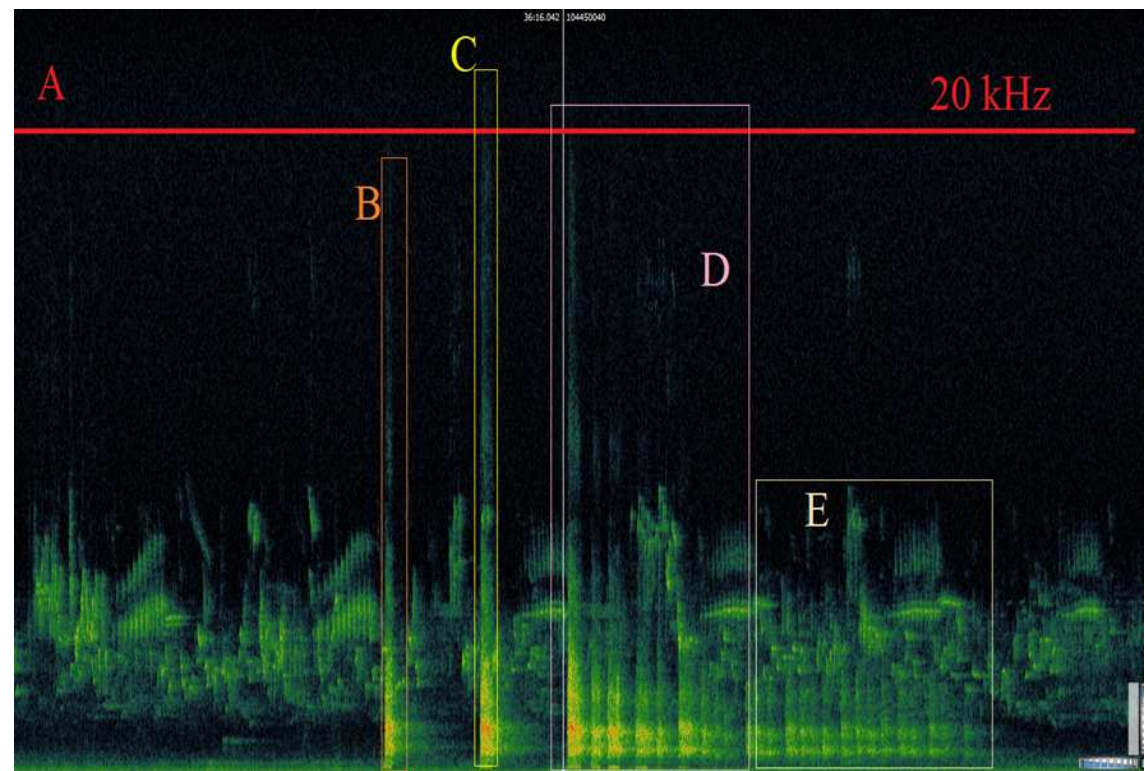

Fig. 2. Spectrogram of bird song and a cry of a frightened male roe deer generated in the Sonic Visualiser (CANNAM et al., 2010) software (B, C, D, E). The spectrogram was generated for the following parameters: scale $\mathrm{dBV}^{2}$, window 1024. The recording was taken deep in Niepołomicka forest on May 1, 2014 at about 3.30 a.m. The low frequency acoustic background comes from the A4 motorway running about $7 \mathrm{~km}$ from the spot where the recording was taken.

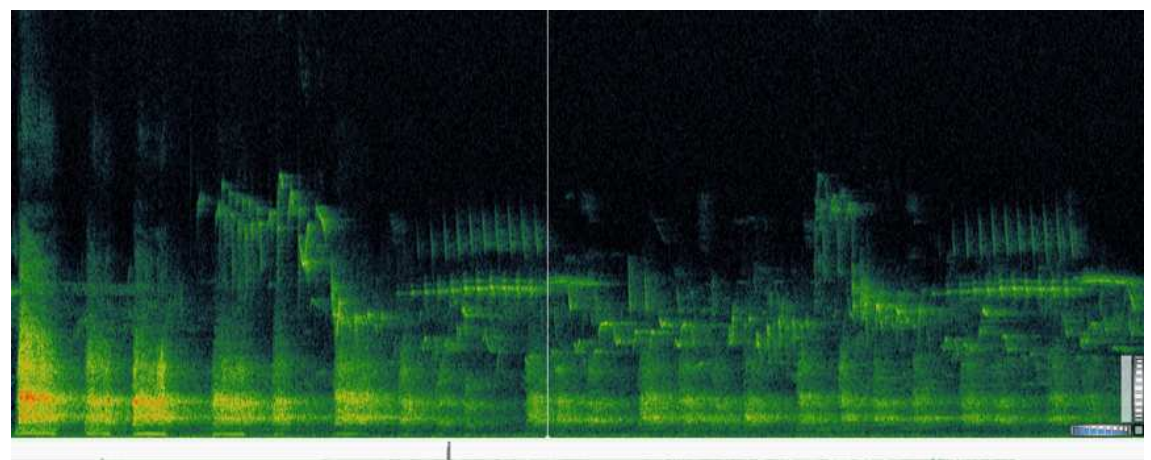

Fig. 3. Zoom-in of the spectrogram representing the cry of a startled male roe deer - areas D and E.

source of the sound, which means that in the laboratory, while listening to the recording, our hearing organs allow us to recognise the direction in which the deer fled. Differentiation of the sounds emitted by different individuals requires developing of special algorithms.

3. Data concerning the species of the animal and, if necessary, its age, sex, and development stage

It was consultation with the foresters that allowed us to determine that what can be heard in the recording is barking of a male roe deer. Roe deer (Capreolus) is an even-toed ungulate belonging to the Cervidae family.

4. Data concerning the animal's physiological condition

In the natural conditions, when the investigations are focused on recording of night and early-morning soundscape and the research team consists only of specialists in acoustics, acquiring of these data is impossible.

5. Data concerning the temperature and humidity

At about 3.30 a.m. on May 1, 2014 in Niepołomicka forest the weather conditions were as follows: no wind, relative humidity $70 \%$, temperature $15^{\circ} \mathrm{C}$, slightly cloudy.

6. Ethological data concerning the behaviour manifested by the animal while producing sounds

The male roe deer was frightened away.

\section{Conclusion}

The paper discusses the research areas that function in modern science on the borderline of two domains - ecology and acoustics. The author explained 
what ideas are included in the concepts of bioacoustics, acoustic ecology, ecoacoustics and soundscape ecology. The results obtained in these domains were compared with those acquired in vibroacoustic studies developed by the researchers from the Department of Mechanics and Vibroacoustics, Faculty of Mechanical Engineering and Robotics AGH University of Science and Technology, as well as the employees of Institute of Machine Design Fundamentals, Faculty of Automotive and Construction Machinery Engineering, Warsaw University of Technology and presented at the annual conference WIBROTECH. Also, the author offers a classification of research topics connected with acoustics and ecology. The second part of the paper presents the possibilities opened by ambisonic technology of recording and decoding the sound for analysis in bioacoustic research.

\section{Acknowledgments}

The project described in this paper has been executed within the project No. 11.11.130.955

Warm gratitude is also addressed to the author's colleagues from the Department of Mechanics and Vibroacoustics of the AGH Cracow University of Science and Technology Cezary Kasprzak, Maciej Kłaczyński, Paweł Malecki, Dominik Mleczko, Janusz Piechowicz, Jacek Wierzbicki, Tadeusz Wszołek who supported the project of structural monitoring research conducted in Niepołomicka forest in 2014 with their time, work, and experience.

The author wants to address her thanks do the employees of the Niepołomice forest region for their friendly welcome and assistance at conducting the research.

\section{References}

1. Baranski R., Kozupa A. (2014), Hand Grip-EMG muscle response, Acta Physica Polonica A, 125, 4A, A-7-A-10.

2. Dąbrowski Z., Engel Z., Kiciński J., Weyna S. (2005), Modern methods of testing vibroacoustic processes [in Polish: Nowoczesne metody badania procesów wibroakustycznych], Biblioteka Problemów Eksploatacji, Wydawnictwo Instytutu Technologii Eksploatacji - PIB, Radom.

3. Batko W., DąBRowski Z., Kiciński J. (2008), Nonlinear effects in technical diagnostics [in Polish], Wydawnictwo Instytutu Technologii Eksploatacji PIB, Radom.

4. Batko W., Pawlik P. (2012), New approach to the uncertainty assessment of acoustic effects in the environment, Archives of Acoustics, 37, 1, 57-61.

5. Cannam C., Landone Ch., Sandler M. (2010), Sonic Visualiser: An Open Source Application for
Viewing, Analysing, and Annotating Music Audio Files, [in:] Proceedings of the ACM Multimedia 2010 International Conference.

6. DąBrowski Z. (1992), The evaluation of the vibroacoustic activity for the needs of constructing and use of machines, Machine Dynamics Problems, Vol. 4.

7. DąBrowski Z., Dziurdź J., Pakowski R. (2013), Selection of sound insulating elements in hydraulic excavators based on identification of vibroacoustic energy propagation paths, Archives of Acoustics, 38, 4, 471478.

8. DĄBrowski Z., DziurdŹ J. (2015), On the need of vibroacoustic axiomatics, Journal of Vibroengineering, 17, 8, 4640-4647.

9. ENGEL Z. (1993), Environmental protection against vibration and noise [in Polish], WN PWN Warszawa.

10. ENGEL Z. (2004), Contemporary methods of investigations of vibroacoustics processes, Mechanika (Kraków), 23, 1, 23-31.

11. Engel Z. (2007), Comparative analysis of correlation and inversion methods applied in vibroacoustic [in Polish], Przegląd Mechaniczny, Stowarzyszenie Inżynierów i Techników Mechaników Polskich, 66, 11, $18-21$.

12. Fabirkiewicz A. (1999), Acoustic environment of animals [in Polish], Rozwój SGGW, Warszawa.

13. FArina A. (2014), Soundscape ecology. Principles, patterns, methods and application, Springer.

14. FARINA A. (1998), Principles and methods in landscape ecology, Towards a Science of the Landscape, Springer.

15. GuŽas D., Genienë V., ŠArlauskas A. (2006), Regional reduction of ecoacoustics related noise pollution, ULTRAGARSAS, 61, 4, 53-57.

16. Jablonski M., Ozga A. (2013), Distribution of random pulses acting on a vibrating system as a function of its motion, AGH University of Science and Technology, Kraków.

17. KAPElański M. (2005), The birth and development of acoustic ecology under the banner of the soundscape school [in Polish], Muzyka, 50, 2, 107-119.

18. Kasprzak C., Skrodzka E., Wiciak J. (2014), The effect of wind turbine infrasound emission on subjectively rated activation level, Acta Physica Polonica A, 125, 4-A, A-45-A-48.

19. KASPRZAK C. (2014), The influence of infrasound noise from wind turbines on EEG signal patterns in humans, Acta Physica Polonica A, 125, 4-A, 20-23.

20. Kelly D.J., Prendergast P.J., Blayney A.W. (2003), The effect of prosthesis design on vibration of the reconstructed ossicular chain: A comparative finite element analysis of four prostheses, Otology \& Neurotology, 24, 1, 11-19.

21. Kleczkowski P., Pluta M. (2012), Normally hearing subjects have no advantage of better audiograms 
in listening tasks, Acta Physica Polonica A, 121, 1-A, A-115-A-119.

22. Klekot G. (2013), Indicator of vibroacoustic energy propagation as a selection criterion of design solution, Archives of Acoustics, 38, 4, 489-494.

23. KompaŁa J. (2005), Methodology for spatial classification of transport routes in the view of their impact on the acoustic climate of the environment, Archives of Environmental Protection, 31, 4, 123-132.

24. Konieczny J., Kowal J., Raczka W., Sibielak M. (2013), Bench tests of slow and full active suspensions in terms of energy consumption, Journal of Low Frequency Noise, Vibration and Active Control, 32, 81-98.

25. OzGA A. (2013), Determining parameters of an $R L C$ circuit response to a single pulse, Acta Physica Polonica A, 123, 6, 1034-1039.

26. OzGA A. (2014), Distribution of random pulses forcing a damped oscillator determined in a finite time interval, Acta Physica Polonica A, 125, 4-A, A-159-A-163.

27. Piechowicz J., Ozga A., Mleczko D., Kasprzak C. StRYCZNIEWICZ L. (2015), Acoustic ecology in forest areas [in Polish], Akademia Górniczo-Hutnicza. Wydział Inżynierii Mechanicznej i Robotyki. Katedra Mechaniki i Wibroakustyki, Kraków.

28. Pijanowski B.C., Villanueva-Rivera L., Dumyahn S.L., Farina A., Krause B.L., Napoletano B.M., Gage S.H., Pieretti N. (2011), Soundscape ecology. The science of sound in the landscape, Bioscience, 61, 3, 203-216.

29. Pearce-Higgins J.W. Leigh S., Langston R.H.W., Bainbridge I.P., Bullman R. (2009), The distribution of breeding birds around upland wind farms, Journal of Applied Ecology, 46, 1323-1331.

30. Rusinski E., Iluk A., Malcher K., Pietrusiak D. (2013a), Failure analysis of an overhead traveling crane lifting system operating in a turbogenerator hall, Engineering Failure Analysis, 31, 90-100.

31. Rusinski E., Moczko P., Pietrusiak D., PrzyBYLEK G. (2013b), Experimental and numerical stu- dies of jaw crusher supporting structure fatigue failure, Strojniski Vestnik Journal of Mechanical Engineering, 59, 9, 556-563.

32. Ryżak M., Bieganowski A., Korbiel T. (2016), Sound wave energy resulting from the impact of water drops on the soil surface, PloS One, 11, 7, 1-12.

33. SCHAFER M.R. (1977), The Tuning of the World, McClelland and Steward Ltd., Nowy Jork, Knopf, Toronto.

34. SCHAFER M.R. (1986), The thinking ear: complete writings on music education, Toronto, Arcana Editions.

35. Sibielak M., Konieczny J., Kowal J., Raczka W., MarszaliK D. (2013), Optimal control of slow-active vehicle suspension - results of experimental data, Journal of Low Frequency Noise, Vibration and Active Control, 32, 99-116.

36. Sueur J., Aubin T., Simonis C. (2008), Seewave. A free modular tool for sound analysis and synthesis, Bioacoustics-The International Journal of Animal Sound and Its Recording, 18, 2, 213-226.

37. Sueur J., FArina A. (2015), Ecoacoustics. The ecological investigation and interpretation of environmental sound, Biosemiotics, 8, 3, 493-502.

38. StęPIEŃ B. (2016), Bootstrap confidence intervals for noise indicators, Acta Acustica united with Acustica, 102, 2, 389-397.

39. Tembrock G. (1959), Voices of animals. Introduction to bioacoustics [in Polish], PWN.

40. Wiciak J., Mleczko D., Ozga A., WszoŁeK G., Wierzbicki J., Piechowicz J., MaŁecki P. (2015), Quietness in the soundscape of the Bialowież National Park, Acta Physica Polonica A, 128, 1-A, A-79-A-84.

41. Wrightson K. (2000), An introduction to acoustic ecology - Soundscape, The Journal of Acoustic Ecology, 1.1, 10-13.

42. Wszolek T., Klaczynski M., Mleczko D., Ozga A. (2014), On certain problems concerning environmental impact assessment of wind turbines in scope of acoustic effects, Acta Physica Polonica A, 125, 4-A, A-38-A-44. 